\title{
ESPACIO DE COYUNTURA: LA ÉTICA PERIODÍSTICA APLICADA A LA COMUNICACIÓN Y A LA GESTIÓN CULTURAL APPLIED TO COMUNICATION AND CULTURAL MANAGEMENT
}

Mtra. Melenie Felipa Guzmán Ocampo ${ }^{1}$

Dra. María José Guillermo Echeverría ${ }^{2}$ Mtra. Yazmin del Carmen Pérez Nares ${ }^{3}$

Universidad Autónoma Del Carmen, México

\section{RESUMEN}

El presente trabajo expone los procesos de análisis y la consecuente apropiación de los principios teóricos de los alumnos del quinto ciclo del Programa Educativo de Comunicación 1 ID 1 $1^{\text {er }}$ autor: ORC ID https://orcid.org/0000-00034012-3630

Docente Investigador Universidad Autónoma Del Carmen mguzman@pampano.unacar.mx

2 ID $2^{\text {do }}$ autor: ORC ID https://orcid.org/0000-00022260-3609

Docente Investigador Universidad Autónoma Del Carmen mguillermo@pampano.unacar.mx

3 ID 3er autor: ORC ID https://orcid.org/0000-00032449-6541

Docente Investigador Universidad Autónoma Del Carmen yperez@pampano.unacar.mx y Gestión Cultural, al verse incitados a confrontar su óptica de las redes sociales como Youtube, Facebook, Instagram, Linkedin y Tumbrl con los principios deontológicos aplicables al ejercicio de su futura profesión; esto como parte de los ejercicios propuestos en la materia: La Ética Periodística Aplicada a la Comunicación y a la Gestión Cultural.

\section{PALABRAS CLAVE}

Ética, Medios de Comunicación, Análisis, Deontología, Redes Sociales 


\section{ABSTRACT}

The present work exhibits the processes of analysis and the resulting appropriation of the theoretical principles of the fifth semester students enrolled in the Academic Program: Comunicación y Gestión Cultural or Communication and Cultural Management, when being encouraged to confront their perspective on social networks such as Youtube, Facebook, Instagram, Linkedin y Tumbrl with the deontological principles applicable to their future professional practice; as part of the exercises proposed in the subject: La Ética Periodística Aplicada a la Comunicación y a la Gestión Cultural or Journalism Ethics applied to Communication and Cultural Management.

\section{KEY WORDS}

Ethics, Media, Analysis, Deontology, Social Networks

\section{INTRODUCCIÓN}

Uno de los valores intrínsecos de los comunicólogos que deciden ejercer el periodismo como profesión, es la ética y los códigos deontológicos emanados de ella, muchas veces presentes en estado latente en los medios de comunicación más no francamente manifiestos. Por lo anterior y como parte de las actividades contempladas en la malla curricular del Programa Educativo de Comunicación y Gestión Cultural que se imparte en la Facultad de Ciencias Educativas de la Universidad Autónoma del Carmen, los estudiantes del quinto ciclo llevaron a cabo un trabajo analítico con respecto a la aplicabilidad de la ética periodística en las redes sociales, de esta forma sus catorce estudiantes plantearon sus propuestas.

Después de haber sido presentados y discutidos en clase los principios éticos que idealmente deben conducir la dinámica de los medios de comunicación, los estudiantes, tomando como referencia de las redes sociales más popularizadas como Facebook, Instagram, Tumbrl, Linkedin y Youtube, propusieron su propia definición de éstas redes, sus estilos de redacción y lineamientos. Una vez delimitados y esclarecidos las directrices y el campo de acción de las citadas plataformas se les solicitó a los alumnos centrar su atención en una de ellas para identificar los trending topics o tendencias dominantes presentes en dicha plataforma y señalar los rasgos, que bajo los principios éticos pudieran ser identificados como "malas prácticas", para posteriormente plantear una propuesta ética, basada en los cuatro modelos expuestos en el ejercicio similar llevado a cabo por José Manuel Blanco López (2011).

\section{METODOLOGÍA}

Bajo los términos propuestos por las Ciencias Sociales en An Expanded Sourcebook. Qualitative Data Analysis, en donde Miles y Huberman (1994), reflexionan en torno al análisis cualitativo y proponen volver la mirada hacia lo vivido por los individuos: "Qualitative data, with their emphasis on people's "lived experience," are fundamentally well suited for locating the meanings people place on the events, processes, and structures of their lifes..." consideramos que el vehículo idóneo para asomarnos a "lo experimentado", o en su sentido más amplio, a los múltiples procesos de construcción del conocimiento, activados en esa búsqueda de articulación en el contexto, fue a partir del análisis de contenido de los textos resultantes del análisis.

El sólo ejercicio de enunciar un mensaje implica un proceso de configuración de la realidad social y de representación del papel que uno mismo concibe desempeñar en ese complejo, los seres se escenifican dotando de sentido el propio entorno. Fue pues a partir del análisis de contenido de los trabajos que se identificaron ciertos elementos persistentes. Sin embargo, 
la constante de más relevancia para los fines específicos de este trabajo es que todos los individuos de la muestra se reconocieron escenificándose, exponiendo sus propios procesos performativos a propósito de su experiencia y análisis de las redes sociales.

Las diferentes reflexiones en torno a la metodología de análisis cualitativo como la que hace H. Russell Bernard (2006) en Research Methods in Anthropology: Qualitative and Quantitative Approaches, enfatiza la idea de que al lidiar con individuos, no debemos perder de vista que como seres humanos de naturaleza dinámica nos valemos de múltiples estrategias para performarnos o representarnos, incluidos los titubeos o rectificaciones, en lo concerniente a este trabajo, las aparentes inconsistencias se conciben como parte de la escenificación performativa de quien emite el discurso.

A partir del análisis de contenido de los trabajos es que fue posible identificar categorías de análisis. Por estrategia metodológica, si bien cada uno de los 13 individuos y sus consiguientes textos será concebido como una "entidad performativa", nos centramos en el análisis de 5 de los 13 trabajos realizados por estudiantes del quinto ciclo de Comunicación y Gestión Cultural de la Facultad de Ciencias Educativas de la Universidad Autónoma del Carmen -que serán referenciados en el documento como estudiantes del 1 al 5-por haber manifestado, a criterio de los presentes autores, un mayor grado de apropiación de los conceptos y su relación con la ética en las redes sociales, los trabajos de referencia representan de manera más patente, un verdadero ejercicio de mediación entre el conocimiento acumulado en estructuras teóricas y la alternativa de una práctica identificada como una opción "ideal" y posible, en la construcción de un verdadero espacio de coyuntura, remitiéndonos a Hugo Zemelman (2009) en Entorno a las funciones analíticas de la totalidad.

\section{DESARROLLO}

En el presente trabajo la ética es la columna vertebral del mismo, por ello se hace referencia a diversas definiciones y aplicaciones del término para conceptualizar su uso.

De acuerdo a Kapuściński (2003) el principal reto para un comunicólogo está en lograr la excelencia en su calidad profesional y su contenido ético. Han cambiado los medios de coleccionar información y de averiguar, de transmitir y de comunicar, pero el meollo de nuestra profesión sigue siendo el mismo: la lucha y el esfuerzo por una buena calidad profesional y un alto contenido ético.

Por otra parte Balderrama (2015) se expresa de la ética de la siguiente forma:

La ética es una ciencia filosófica y práctica, pero también teórica, normativa, que descubre y fija normas, consejos y advertencias para que el hombre y la mujer vivan bien.

La ética tiene una faceta, una dimensión personal en la búsqueda de la excelencia, de la perfección personal, y una faceta social o colectiva de nuestras relaciones con los demás y lo que queremos hacer juntos como ideal. La moralidad, el honor, la honestidad, el respeto, el deber, la responsabilidad social y la obligación de conciencia referidos al ejercicio de una profesión es lo que conocemos como deontología o ética profesional.

Por su cuenta Restrepo y Botello (2018) hacen énfasis en el valor que puede denominarse ético desde la invención de la imprenta y con anterioridad al trabajo de los copistas, es así que establecen:

"No es una nueva ética, son nuevas aplicaciones de la ética los que se hacen 
en la era internet; no es cuestión de adecuaciones con lo que esta palabra alude a oportunismos utilitarios; son respuestas de la ética a circunstancias nuevas. Esas respuestas se dan a partir de los principios de siempre que les dan valor a las formas de comunicación entre los humanos, de modo que, como ha sucedido con los códigos de la radio o la televisión y de los medios impresos, sucede con internet: aparecen los códigos como respuesta a las necesidades que induce este medio".

Es así que los trabajos realizados por los estudiantes están fundamentados, para este trabajo, en el uso crítico de la teoría de Hugo Zemelman (2009), basándonos en la premisa de la crítica como razonamiento epistemológico y la continua redefinición de los conceptos partiendo del propio conocimiento.

Durante el curso los estudiantes debieron elegir dos redes sociales para analizarlas y contrastar el uso cotidiano que ellos mismos les dan y características que les atribuyen con el andamiaje teórico cimentado desde el curso de Ética Aplicada a la Comunicación y Gestión Cultural. El objeto de este ejercicio fue habilitar a los estudiantes para ser capaces de discernir desde la experiencia individual lo que ellos perciben como "no correcto" en el uso de las redes sociales con contenidos periodísticos y de las publicaciones que con tal de tener la primicia en una nota no verifican, violan derechos humanos y leyes de protección de datos, entre otros aspectos.

Por otra parte, el ejercicio periodístico ha añadido a su rango de alcance las multiplataformas, entre ellas el internet, al respecto en el periódico Excelsior se puede consultar que "En México, hay una población de más de 120 millones de habitantes, de los cuales, alrededor de 63 millones están conectados a internet $y$ son usuarios de perfiles en alguna red social”, aseguró Leobardo Hernández Audelo, maestro en Ciencias Computacionales por la UNAM.

La Asociación de Internet.mx presentó la edición $14^{\circ}$ del Estudio sobre los Hábitos de los Usuarios de Internet en México 2018 en donde se destaca que en nuestro país el uso de redes sociales es la actividad preponderante de los mexicanos en internet.

Por todo lo anterior los medios de comunicación han encontrado un nicho de oportunidades para que las noticias sean inmediatas y de consumo viral, lo que hace que en muchas de las ocasiones los usuarios compartan sin necesariamente corroborar que lo que se dice sea fidedigno. El mismo estudio hace referencia a que las redes sociales más usadas por los mexicanos son: en primer lugar Facebook, seguida de Whatsapp, Youtube, Twitter e Instagram.

Para que los estudiantes tuvieran las bases teóricas y pudieran realizar un ejercicio individual analítico conocieron el origen del término ética y su diferencia con la moral.

Si el término moral procede del vocablo latino que significa costumbre, la palabra ética deriva de ethos, que en griego significa carácter (es evidente la relación entre ambos). De igual manera conocieron teorías éticas como: Formalismo, Ética discursiva, Estoicismo, Intelectualismo moral, lusnaturalismo ético, Utilitarismo y Hedonismo.

Dotados de estos referentes a los estudiantes se les instó a responder preguntas como: ¿Quién puede decirme lo que debo hacer?, ¿Qué debo hacer?, ¿Cuáles son las acciones correctas?, ¿Puedo conocer lo que está bien y lo qué debo hacer?

Con la información obtenida los estudiantes definieron las redes sociales que usaron como referencia, sus manuales o estilos de redacción para las redes, las malas prácticas identificadas, los trending topics y una propuesta de código deontológico, basándose en un ejercicio similar 
realizado por José Manuel Blanco López en 2011.

\section{ESTUDIANTE 1 DEFINIÓ INSTAGRAM:}

Es una red social y aplicación originalmente para subir fotos en específico y ahora también para videos cortos.

En enero de 2011, Instagram añadió "hashtags" para ayudar a los usuarios a descubrir las fotos que los demás usuarios compartirían sobre un mismo tema.

\section{LINKEDIN:}

Es una comunidad social orientada a las empresas, negocios y empleos. Partiendo del perfil de cada usuario, que libremente revela su experiencia laboral y sus destrezas, la web pone en contacto a millones de empresas y empleados.

\section{ESTUDIANTE 2 DEFINIÓ FACEBOOK:}

Es una de las redes sociales más utilizadas en la actualidad, cuanta con más de 1,94 mil millones de usuarios activos. Los usuarios pueden agregar a otros usuarios como "amigos», intercambiar mensajes, publicar actualizaciones de estado, compartir fotos, vídeos y enlaces, usar varias aplicaciones de software y recibir notificaciones de la actividad de otros usuarios. Además, los usuarios pueden unirse a grupos de usuarios de interés común organizados por lugar de trabajo, escuela, pasatiempos u otros temas, y categorizar a sus amigos en listas como "Personas del trabajo» o «Amigos cercanos». También proporciona opciones para reportar o bloquear a personas desagradables 0 amistades no deseadas.

\section{INSTAGRAM}

Es una red social y aplicación para subir fotos y vídeos. Sus usuarios también pueden aplicar efectos fotográficos como filtros, marcos, similitudes térmicas, áreas subyacentes en las bases cóncavas, colores retro, y posteriormente compartir las fotografías en la misma red social o en otras como Facebook, Tumblr, Flickr y Twitter. Una característica distintiva de la aplicación es que da una forma cuadrada a las fotografías en honor a la Kodak Instamatic y las cámaras Polaroid, contrastando con la relación de aspecto $16: 9$ y 4:3 que actualmente usan la mayoría de las cámaras de teléfonos móviles. Hoy en día, las fotos pueden estar en horizontal y en vertical sin el uso de bordes blancos, aunque estas son recortadas parcialmente. También hay un medio de comunicación privado para hablar llamado Instagram Direct.

\section{ESTUDIANTE 3 DEFINIÓ YOU TUBE}

YouTube es un portal de internet que permite a sus usuarios subir y visualizar videos. Fue creado en febrero del 2005. Ha sido diseñada para alojar vídeos que los usuarios puedan consumir cuando les apetezca. Además, a través de ella también puedes emitir vídeos en directo y grabarlos para compartirlos posteriormente. Podríamos considerarla como un tipo de televisión a la carta, además de una red social audiovisual, dado que puedes permitir que otros usuarios se suscriban a tu propio canal y que comenten tus contenidos, para así obtener feedback de tus seguidores y suscriptores.

\section{TUMBLR}

Tumblr es una plataforma para crear micro blogs sociales, en los que es posible publicar textos, imágenes, videos, citas, enlaces, archivos de audio y conversaciones tipo chat. Permite fácilmente crear blogs con un gran atractivo visual, cuenta con atractivas plantillas y diseños, puede ser integrado con otras redes y aplicaciones sociales, permite publicar actualizaciones rápidamente, las actualizaciones pueden contener etiquetas y es fácil compartir actualizaciones de otras personas. 


\section{ESTUDIANTE 4 DEFINIÓ FACEBOOK:}

Facebook es un sitio de Internet que teje una amplia red de personas, instituciones, organizaciones sociales y escuelas, entre otras que quieren relacionarse.

\section{Instagram}

Instagram es una aplicación que actúa como red social ya que permite a sus usuarios subir cualquier tipo de fotos y videos, con la opción de aplicar diversos efectos fotográficos, como por ejemplo, filtros, marcos, similitudes térmicas, colores retro, o vintage, para compartirlas no sólo en Instagram, sino en Facebook, Twitter, Tumblr y Flickr.

\section{FINALMENTE EL ESTUDIANTE 5 DEFINIÓ FACEBOOK:}

Es un servicio gratuito que permite conectar a las personas en internet. $\mathrm{Si}$ somos usuarios registrados en su página web, podremos gestionar nuestro propio espacio personal: crear álbumes de fotos, compartir vídeos, escribir notas, crear eventos o compartir nuestro estado de ánimo con otros usuarios de la red.

\section{INSTAGRAM}

Es la red social en continua tendencia, mejor conocida dentro del grupo de aplicaciones conocidas como coolmedia (redes sociales de moda). Estas redes sociales actualmente son las que más crecimiento tienen y el tiempo de uso que hacen sus usuarios en ellas es bastante elevado.

\section{RESULTADOS}

Este trabajo se llevó a cabo bajo un diseño cuasi experimental, ya que se optó por analizar 5 de los 13 trabajos llevados a cabo en las sesiones de clase porque, como se hizo mención antes, estos 5 individuos cuyos textos se toman como referencia, se destacaron por evidenciar un análisis y apropiación más compleja de los conceptos previamente presentados y discutidos en clase.

La figura 1 ilustra las redes sociales analizadas:

Figura 1 Redes sociales analizadas por los estudiantes.

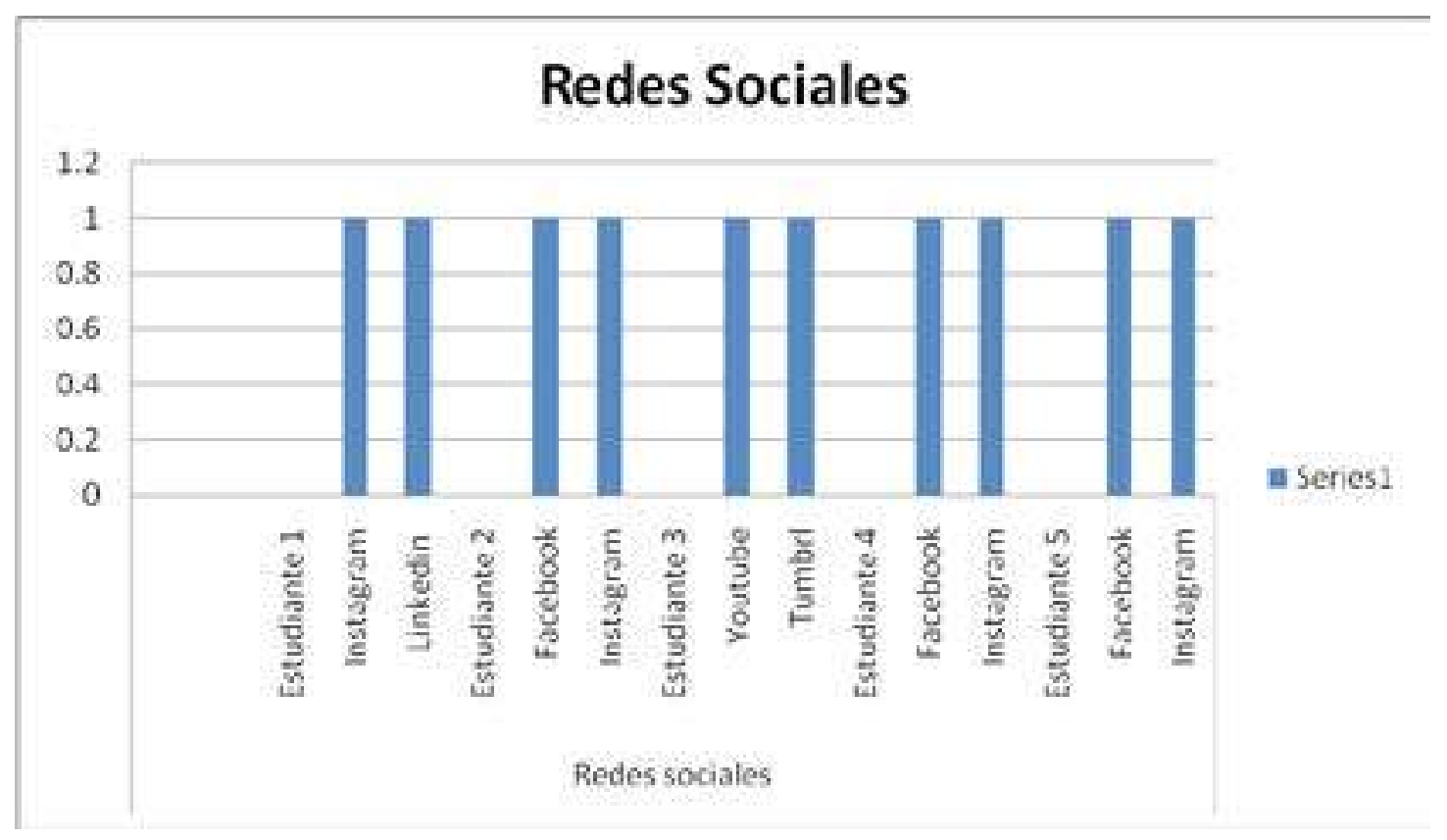


De los cinco ejercicios dos estudiantes no refirieron manuales de estilo para las redes que analizaron, tres de ellos presentaron dos, uno por cada red social elegida., como se puede ver en la figura 2.

Figura 2. Número de manuales de estilo para usar las redes sociales.

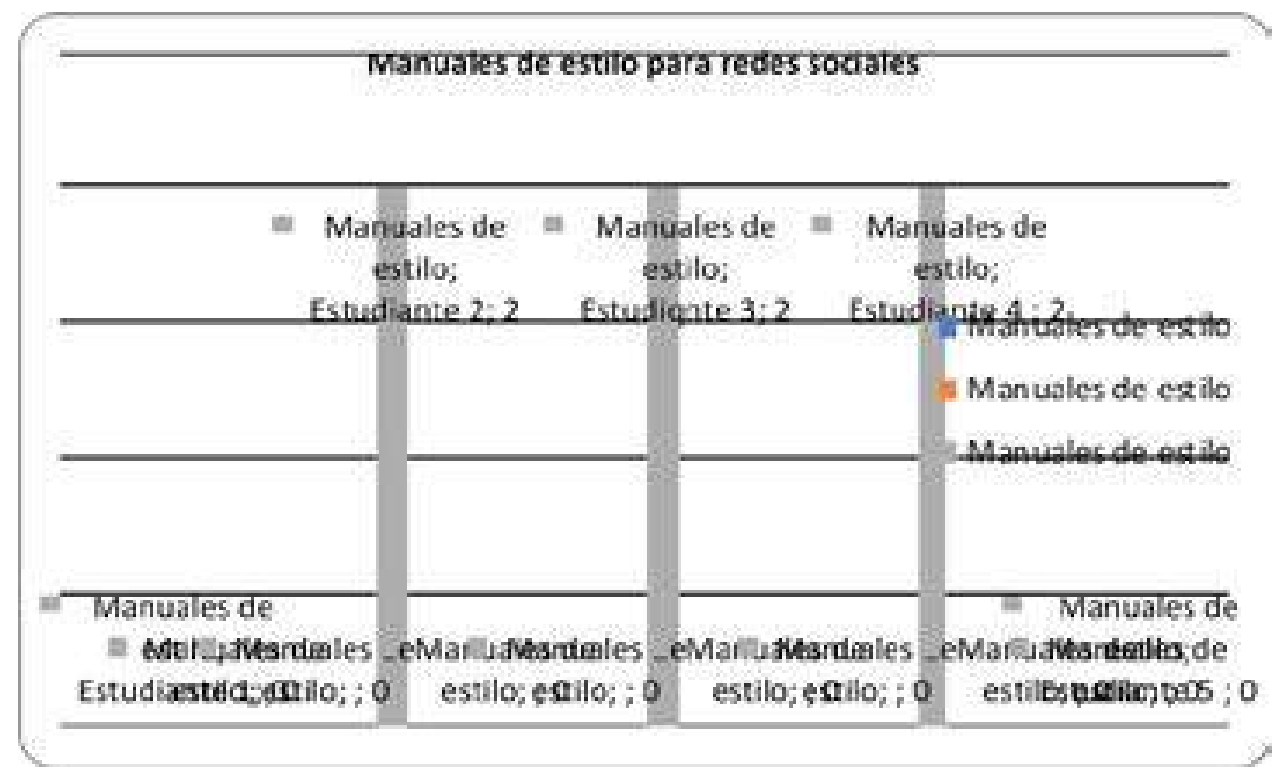

Los elementos constantes manifiestos en la concepción que los individuos de la muestra tienen de las redes sociales son el uso de verbos de acción relacionados a la información concebida como un ente capaz de ser alojado, gestionado y revelado una vez inmerso en el flujo de una red social.

Posteriormente y como parte del ejercicio analítico, ellos tomaron como marco de referencia cuatro modelos para el análisis de la aplicación de la ética periodística en las redes sociales: Deontológico, Maquiavélico, Virtuoso y Utilitarista.

En este apartado, como muestra, se ilustra con tres ejemplos de lo analizado:

\section{ESTUDIANTE 2}

Modelo Deontológico: Publicar contenido actualizado, utilizar las noticias en Facebook como un medio confiable, en el que el espectador sepa que la información es confiable. En el caso de Instagram, hacer videos en vivo los cuales se pueden volver populares en un instante.

Modelo Utilitarista: Poder utilizar Instagram para ver videos cortos, que se basen en memes que pueden ser extractos del suceso más reciente que haya sucedido (una entrega de premios, por ejemplo)

Modelo Maquiavélico: Llegar a un suceso, a segundos de que haya iniciado, da la ventaja de que se puede publicar lo más pronto posible, grabar en vivo en Facebook - Instagram, puede lograr que esta información llegue a las personas con más rapidez.

Modelo Virtuoso: Utilizar estas redes sociales de la mejor manera, no mal informando al espectador, ni mucho menos 
tener pocas fuentes, lo cual puede llevar a la nota al fracaso.

De este futuro comunicólogo destacan las referencias que hace al tiempo, hace uso de términos diversos para hacer alusión a la premura y optimización temporal: "actualizado", "cortos", "reciente", "pronto" y "rapidez" son algunos de estos términos.

\section{ESTUDIANTE 3}

\section{Modelo deontológico:}

La web arroja la siguiente información:

"El contenido de este código tiene como objetivo mejorar el tratamiento informativo de algunas de las cuestiones sociales de mayor actualidad. Las recomendaciones que desarrolla en su interior deben ser puestas en práctica no sólo por los profesionales de los medios, sino paralelamente, por los estudiantes de comunicación que serán los que ocupen dichos puestos el día de mañana. De este modo, los pupilos deben asimilarlos como eficientes y útiles, especialmente porque en el mundo laboral del periodismo no tiene cabida el informador que no respete el código deontológico, que engloba lo siguiente:

- El respeto a la verdad.

- Estar abierto a la investigación de los hechos.

- Perseguir la objetividad, aunque se sepa inaccesible.

- Contrastar los datos con cuantas fuentes periodísticas sean precisas.

- Diferenciar con claridad entre información y opinión.

- Enfrentar, cuando existan, las versiones sobre un hecho.

- Respeto a la presunción de inocencia.

- Rectificación de las informaciones erróneas."
Definiendo así el modelo, podemos analizar el uso de YouTube como no regulado del todo, pues existe como en todo medio comunicativo, información falsa que circula y afecta a la población en su formación. Si hablamos de los trending topics en la plataforma de audiovisuales, normalmente se encuentran videos de tutoriales o música, que de alguna u otra manera, es bueno. Adentrándonos en el ámbito periodístico, muchas televisoras le han aportado a un canal que sirva como televisión online, noticieros, reportajes, entre otros trabajos son encontrados en la nube. El trabajo de los nuevos periodistas o comunicadores es verificar la información, trabajarla, producirla y posteriormente hacer viral algo que sea de calidad y nutra el conocimiento o acervo cultural, ya que, al existir pocas limitantes con la verificación de la información, es difícil diferenciar cual es la correcta, aunque gracias a los trending topics de la red, podemos ver cual es la más verídica.

Una ventaja que tiene esta, es la opinión de diversos perfiles y personalidades de distintas partes, que dan paso al dialogo acerca de alguna situación.

En el caso de Tumblr, que es un blog de información, el nuevo periodista tiene que atender este tipo de redes, las cuales son más conocidas por las fotografías virales sin profundo contenido que por su misma finalidad. Al ser algo similar a Facebook es necesario regular las publicaciones y poder utilizar distintas plataformas para llenar de información eficaz y verídica.

\section{MODELO UTILITARISTA:}

En este modelo, podemos decir que afirmativamente como lo menciona el documento en el cual está basado este trabajo, se encuentra justificada la información considerada como "espectáculos" o "farándula" pues cabe mencionar que las redes sociales 
son también formas de entretenimiento para las personas, entonces, el hecho que exista videos de risa, chistes, información de famosos o resúmenes de novelas, también son válidas, pero no entran dentro del trabajo del periodista. En el blog como Tumblr sucede lo mismo, no es "pecado" compartir información graciosa, lo malo es cuando utilizamos estas redes sociales para afectar vidas o dañarlas, e incluso para compartir información o fake news. En estos años, la tecnología es utilizada como un todo, algo que resuelve nuestra vida, e incluso se ha vuelto una fuente de ingresos.

\section{MODELO MAQUIAVÉLICO:}

Hoy en día los videos que son publicados o las entradas en los blogs, tienen demasiada competencia, pues todo poco a poco se introduce en lo digital y lo importante para los generadores de productos en estas redes sociales es la primicia, aunque esto pueda afectar la veracidad. Me recuerda el caso del ciclista fallecido al caer del puente de isla aguada en Campeche. El joven quien no pudo ser rescatado y fue jalado por el mar, se encontraba desaparecido, y los medios con tal de ser leídos, publicaban datos de la supuesta persona y otros, videos con el título de "Rescatado con vida", cuando el joven aún se encontraba en calidad de desaparecido. De nueva cuenta, no importa cómo, lo importante es llegar primero.

\section{Modelo virtuoso:}

Se pueden analizar ambas redes sociales desde el punto que ambas tienen la virtud de informar, de transmitir entrevistas, noticias, entre otros trabajos, en los cuales sin duda se tiene el poder de la palabra, de tratar a cualquier asunto o temática sin estar a favor o en contra de alguna creencia o partido, ser neutral y hablar en pro de la información. Que mejor que aprovechar esas virtudes del periodismo online para realizar trabajos exitosos. Desgraciadamente en nuestro entorno o país, aun existe el mal uso siempre poniendo atención a disputas o comentarios acerca de las preferencias del medio de comunicación.

Del texto-reflexión de este alumno, se evidencia su preocupación hacia conceptos morales como la verdad, la claridad y la ausencia de regulación de la información presentada desde estos canales. También establece manifiesta su comprensión de los mensajes en los medios de comunicación como potencialmente "fríos" o "calientes" -como plantea McLuhan- de acuerdo a la latente posibilidad de respuesta del receptorpotencial interlocutor del diálogo establecido a partir de las diferentes plataformas informativas analizadas. Esta última reflexión construye al receptor desde su carácter de "agente", reconociendo su carácter activo en la recepción de una determinada información.

\section{ESTUDIANTE 3}

Modelo deontológico. Es importante no perder la visión periodística, el hecho de verificar las fuentes, es clave. Tener en cuenta que no solo es para informar, sino que es cómo se informa, para que, qué tanto puede impactar. Estar consiente que nuestras acciones tienen reacciones. En redes sociales o en cualquier medio, nuestro deber es hacer periodismo de la mejor forma posible.

Modelo utilitarista. Las redes sociales vinieron a reformar muchas de nuestra costumbre, entre ellas nuestros medios de comunicación, pero hay que ver esto cono una herramienta del medio y no como un tope de trabajo, se puede sacar provecho desde el hecho de la inmediatez, la capacidad de ser leído, pero también de brindar algo interesante para leer.

Modelo maquiavélico. "El fin justifica los medios", debemos apartarnos a nuestro entorno en busca de oportunidades, abrirnos camino hacia una visión más amplia y para ellos las redes sociales nos lo pueden proporcionar, cada 
uno es responsable de lo que escribe o dice y en el periodismo es más importante, cómo se dice.

Modelo virtuoso. Pensar en los medios que poseemos, entendiéndose por medios algo no material, luego las habilidades que se desarrollan a lo largo de la carrera, estas se pueden poner en práctica en cualquier medio, no es diferente en las nuevas plataformas, solo es buscar las maneras a adecuadas por un bien común, donde puede pensar no por los demás, sino como los demás.

De este alumno destaca también su alusión a términos relacionados con el tiempo, pero también manifiesta su preocupación por el impacto de la verdad en la dinámica social, destacando las posibles consecuencias de una determinada nota, que idealmente, debería promover y anteponer siempre el bien común.

\section{CONCLUSIONES}

Del trabajo realizado por los estudiantes se evidencia que son capaces de identificar los códigos éticos que todo comunicólogo que decide ejercer el periodismo debe tener en cuenta, así la conclusión del trabajo del estudiante 1 dice:

Instagram y Linkedln son plataformas quizá diferentes, pero comparten rasgos similares para actualizar de forma inmediata nuestra vida cotidiana en una, y en la otra un revulsivo para catapultarnos profesionalmente.

Mi trabajo no se inclinó hacia el ámbito periodístico, pero sí a la ética que debemos tener en cuanto a las herramientas que existen como estas dos aplicaciones que pueden formarnos profesionalmente, dándoles el uso adecuado y es allí donde se entrelazan, pues es importante hoy en la era digital tener fuentes a través de la web donde podamos subir o publicar nuestro trabajo o actividades; porque es lo que buscan las empresas de hoy.
$Y$ es que es uno de los temas más vistos actualmente y lo que precisamente vimos en el foro realizado en la facultad de educación de la UNACAR "Las TIC's y su impacto en los procesos y problemáticas del área de humanidades", pues lo de hoy es dejarse ver por medio de estas aplicaciones y plataformas para generar un curriculum e historial, que nos dará la oportunidad de convertirnos también en una marca si así lo deseamos, pero yendo de la mano con la ética para usar adecuadamente cada aplicación, herramienta o plataforma que nos ofrece el internet"

\section{LA CONCLUSIÓN DEL ESTUDIANTE 2:}

No hay duda de que las redes sociales llegaron a la humanidad para facilitar muchas cosas a la vida cotidiana. Uno de los principales usos, son el informar los acontecimientos más recientes, en estos tiempos de la información tras mediática, nos damos cuenta de que el utilizar más de una red social, nos nutre, el sentido de que no vamos a ver lo mismo.

El mal uso que se la ha dado a las redes sociales ha llegado a un punto en el que las personas piensan que son realmente peligrosas, cuando no se han dado cuenta que son de gran ayuda.

\section{CONCLUSIÓN DEL ESTUDIANTE 3:}

Tanto YouTube como Tumblr, son regidas por sus propias políticas que son establecidas con el fin de que el usuario que haga uso de ellas actúe conforme a su ética conociendo los debidos reglamentos y utilidades. Hoy en día no existe una regulación de las redes sociales que impida el mal uso de información a la hora de realizar periodismo, lo cual es en parte cubierto por los distintos manuales creados en diferentes lugares e instituciones, aunque solo abarcan estilos.

Es de suma importancia que, al no haber 
un control, la sociedad actúe conforme los lineamientos para una sana convivencia social. El periodista actual tiene una gran labor como comunicador, de verificar fuentes, regular los medios y redes, pues su trabajo no solo es escribir.

\section{CONCLUSIÓN ESTUDIANTE 4:}

Lo positivo dentro de esta situación es la modernización de los medios de comunicación y la inmediatez que nos ha brindado una mayor información en el momento en el que el suceso ocurra y a través de esto contribuir de una manera adecuada en medio de las situaciones críticas que se presentan. Lo aparentemente negativo es el correcto uso de la ética dentro de estos medios de comunicación que por querer informar y tener la primicia dentro de su audiencia se han olvidado de la integridad de los involucrados y el tipo de información verídica que se le da a la audiencia o público.

Los medios de información han evolucionado y lo ideal es que las maneras en las que se tiene en cuenta a la sociedad también deberían hacerlo. No hay porque prostituir el trabajo de un comunicador, no tienen que venderse al mejor postor o partido político que les garantice algún tipo de beneficio. Es necesario regresar al origen y la esencia del periodismo como fuente de denuncia, de contrapeso social, político y económico sigue siendo la fuente de su legitimidad en la comunidad. No hay porque desviar el verdadero significado de los medios de comunicación dentro de la sociedad. Debe evitarse en medida de lo posible dañar al usuario o receptor de la información, es necesario procurar en todo momento por su bienestar, ya basta de denigrar esta profesión que en su origen su objetivo era ser la voz de los que no tenían, ver por el bienestar de la sociedad brindando información que ayude a que la verdad sea la única que se dé a conocer.

\section{CONCLUSIÓN ESTUDIANTE 5}

La versatilidad de cualquier periodista, define hasta dónde llegara, no es necesario adaptarnos a los medios, si no ver estos como una herramienta productiva, que ayudará a difundir la información con mayor alcance y realce. Siempre debemos estar en constante inquietud por lo que se está haciendo, no dar por aprendido, ni sabido nada, la verdad absoluta no la tenemos, solo somos facilitadores de información, a lo cual las personas nos darán la confianza y credibilidad de entrar en su día a día, donde clara mente el medio o el periodista que pierda esa credibilidad, puede dejar de hacerse llamar periodista.

Las redes han venido a reformar y transformar el periodismo, a llevarlo hasta sus límites, pero no hay que confundir las cosas, no por el hecho de ser el más leído, significa que voy a sacar cualquier cosa, dejarme llevar por la pereza de inmediatez.

La realidad en la que vivimos nos exige ser más críticos, más analíticos y sobre todo más versátiles, para adaptarnos a las nuevas formas del periodismo, porque o nos adaptamos o nos quedamos.

A partir de este ejercicio realizado por los estudiantes, nosotros como profesores investigadores podemos concluir que a lo largo del curso les fueron proporcionadas las bases teóricas de la ética periodística y ellos fueron capaces de apropiárselas y visualizar su articulación en la futura práctica profesional. La dinámica impresa en las redes sociales es manifiestamente concebida como un proceso y un constructo del cual tanto los profesionales como los no profesionales de los medios de comunicación formamos parte, ejercer su criterio ético al momento de insertarse en ese engranaje inevitablemente presentará variaciones de un individuo a otro ya que la aplicación de la ética es el resultado de las decisiones de conciencia individual. 


\section{REFERENCIAS BIBLIOGRÁFICAS}

Balderrama (2015) Deontología periodística un camino urgente a seguir. Universidad Autónoma de Chihuahua. México

Bernard, H. Russell (2006, 4th Edition) Research Methods in Anthropology: Qualitative and Quantitative Approaches. London: AltaMira Press,

México, cuarto lugar en uso mundial de redes sociales, (18 de enero de 2018), Excelsior, recuperado el día 31 de enero de 2019 https://www.excelsior.com.mx/ hacker/2018/01/18/1214650

Miles and Huberman (1994) An Expanded Sourcebook. Qualitative Data Analysis. 2 ${ }^{\text {nd }}$. edition. California: SAGE Publications.

Restrepo y Botello (2018) Ética periodística en la era digital. International Center Journalists. Washigton DC

7 Gráficos de usuarios e internet en México 2018 (17 de mayo de 2018), El Economista. Recuperado el 31 de enero de 2019 https://www. eleconomista.com.mx/tecnologia/7-graficossobre-los-usuarios-de-internet-en-Mexicoen-2018-20180517-0077.html

Kapuscinski (2003) Los cinco sentidos del periodista (estar, ver, oír, compartir, pensar) Fundación para un nuevo periodista iberoamericano. Fundación Proa. México 